\title{
Properties and Kinetics of Selective Zinc Leaching with Choline Chloride and Urea
}

\author{
Jinxia Zhang ${ }^{1,2}$, Jiajing Dong ${ }^{1}\left(\mathbb{D}\right.$, Fusheng Niu ${ }^{1,2, *}$ and Chao Yang ${ }^{1}$ \\ 1 College of Mining Engineering, North China University of Science and Technology, Tangshan 063210, China; \\ kyky@ncst.edu.cn (J.Z.); dongjiajing@stu.ncst.edu.cn (J.D.); yc17367534003@stu.ncst.edu.cn (C.Y.) \\ 2 Hebei Key Laboratory of Mining Development and Safety Technology, Tangshan 063009, China \\ * Correspondence: niufusheng@ncst.edu.cn; Tel.: +86-1823-2585-555
}

Citation: Zhang, J.; Dong, J.; Niu, F.; Yang, C. Properties and Kinetics of Selective Zinc Leaching with Choline Chloride and Urea. Minerals 2021, 11, 857. https://doi.org/10.3390/ $\min 11080857$

Academic Editor: Kenneth N. Han

Received: 24 June 2021

Accepted: 6 August 2021

Published: 9 August 2021

Publisher's Note: MDPI stays neutral with regard to jurisdictional claims in published maps and institutional affiliations.

Copyright: (c) 2021 by the authors. Licensee MDPI, Basel, Switzerland. This article is an open access article distributed under the terms and conditions of the Creative Commons Attribution (CC BY) license (https:// creativecommons.org/licenses/by/ $4.0 /)$.

\begin{abstract}
A choline chloride-urea (ChCl-urea) deep eutectic solvent (DES) was used to experimentally investigate the secondary recovery of zinc from zinc-bearing dust sludge via a leaching process. The effects of varying the liquid-solid ratio, leaching temperature, stirring speed, and leaching time on the zinc leaching efficiency were determined, and the optimum values of these parameters were found to be $15: 1,90^{\circ} \mathrm{C}, 400 \mathrm{rpm}$, and $600 \mathrm{~min}$, respectively, at which a leaching efficiency of $86.87 \%$ was achieved. XRF and EDS analyses confirmed that the zinc content in the sludge decreased noticeably after leaching, while those of other elements did not, indicating the selective and efficient leaching of zinc. A study of the leaching kinetics showed that the reaction conforms to the nuclear shrinkage model without solid product layer formation, and the calculated apparent activation energy is $22.16 \mathrm{~kJ} / \mathrm{mol}$.
\end{abstract}

Keywords: deep eutectic solvent; zinc-bearing dust sludge; selective leaching; kinetics; zinc oxide

\section{Introduction}

Zinc is an important raw material for the national economy of China. Over the past two decades, the country's demand for this material has continued to grow. The proportion of zinc consumed by China in relation to global zinc consumption increased from $15.18 \%$ in the year 2000 to over $50 \%$ by 2020 , and the total amount of zinc consumed by the country stands at 6.42 million metric tons [1-4]. Although China is a large zinc producer, the poor endowment of primary zinc mineral resources and the resource exhaustion resulting from many years of mining have resulted in its dependence on imported zinc exceeding $35 \%$, which affects the country's strategic resource security [5-7]. To maximize resources, the recovery of zinc from zinc-bearing waste is becoming increasingly important; however, such waste is difficult to recycle due to the wide range of sources of varying quality and the increased potential for secondary pollution. Hence, it is important for the zinc recycling industry to be developed in a green and efficient way.

There are many ways to use zinc-bearing dust sludge, including the extraction of valuable metals or direct materialization. Yang [8] prepared $\alpha-\mathrm{Fe}_{2} \mathrm{O}_{3} / \mathrm{ZnFe}_{2} \mathrm{O}_{4}$ using blast furnace dust as a raw material. The product showed good photocatalytic degradation activity for the methylene blue group and realized the resource utilization of zinc-bearing dust sludge. Gong [9] used a zinc volatilization roasting-magnetic separation process to recycle the zinc in high zinc-bearing dust sludge. However, a large amount of both zinc oxide and iron oxide were reduced simultaneously during roasting, resulting in high carbon consumption, while the volatilization of zinc in the high-temperature environment resulted in a large amount of energy wastage. Additionally, traditional acid leaching or alkali leaching methods can be used to extract zinc, although both these approaches suffer from drawbacks. Specifically, acid leaching will tend to dissolve not only zinc but also other metallic substances present in the zinc-containing dust sludge, such as iron and calcium. Alternatively, when alkali leaching is used, a high zinc leaching efficiency cannot 
be obtained as the alkaline solution can only dissolve the zinc oxide present in the sludge and not the zinc ferrite [10-12]. However, in both types of processes, the corrosive nature of the solutions can lead to equipment damage and environmental pollution.

Compared to traditional zinc extraction processes, the use of deep eutectic solvents (DESs) offers significant advantages due to their excellent physical and chemical properties [13]. In recent years, research into the application of such solvents in the separation of mixtures has gradually increased, and their use in fields such as the dissolution of metal minerals and sewage treatment has become increasingly widespread [14-16]. ChCl-urea DESs, in particular, have been shown to possess a unique selective dissolution ability for $\mathrm{ZnO}$. During the leaching process, these solutions undergo a complexation reaction with $\mathrm{ZnO}$ to form $\left[\mathrm{ZnOCl}\left(\mathrm{NH}_{2} \mathrm{CONH}_{2}\right)_{2}\right]^{-}$[17], thereby enabling the extraction of metallic zinc. Against this backdrop, the present study uses an experimental approach to investigate the leaching of zinc oxide from zinc-bearing dust sludge using a ChCl-urea DES with a ChCl:urea molar ratio of 1:2. To optimize the process, the effects of varying the key parameters such as the liquid-solid ratio, leaching temperature, leaching time, and stirring speed are investigated. In addition, the kinetics of the leaching reaction is studied based on the nuclear shrinkage model. The goal is to develop a simple method for the recovery of zinc from zinc-bearing dust sludge. The process effectively avoids the corrosion of strong acid and alkali, and a high-temperature environment with high energy consumption which will significantly reduce the cost of utilizing or recycling zinc-bearing dust sludge.

\section{Materials and Methods}

\subsection{Properties of Zinc-Bearing Dust Sludge}

The zinc-bearing dust sludge used in the experiments was obtained from a steel plant in Antai, Shanxi, China. Its chemical element analysis (Table 1) reveals that the chemical composition of the sample is complex, with the main elements present being $\mathrm{Fe}, \mathrm{Zn}$, and Si. In terms of compounds present, the proportions of $\mathrm{ZnO}$ and $\mathrm{Fe}_{2} \mathrm{O}_{3}$ were $12.98 \%$ and $35.11 \%$, respectively. It is also worth noting that the chlorine content of the sludge was $5.76 \%$. When chlorine is present, it will undergo chlorination reactions with water to produce corrosion-causing acid, while simultaneously undergoing replacement reactions with $\mathrm{Fe}_{2} \mathrm{O}_{3}, \mathrm{ZnO}$, and other metal oxides in the sludge, thereby accelerating the corrosion of the metal oxide surface.

Table 1. Chemical multielement analysis of zinc-bearing dust sludge (wt.\%).

\begin{tabular}{cccccccccc}
\hline Element & $\mathrm{TFe}$ & $\mathrm{ZnO}$ & $\mathrm{SiO}_{2}$ & $\mathrm{Cl}$ & $\mathrm{Al}_{2} \mathbf{O}_{3}$ & $\mathbf{C a O}$ & $\mathbf{P b O}$ & $\mathbf{M g O}$ & $\mathbf{K}_{2} \mathbf{O}$ \\
\hline wt. \% & 35.11 & 12.98 & 6.08 & 5.76 & 3.86 & 3.70 & 2.13 & 2.04 & 1.30 \\
Standard deviation & 0.01 & 0.02 & 0.01 & 0.01 & 0.03 & 0.01 & 0.02 & 0.01 & 0.01 \\
\hline
\end{tabular}

Laser particle size analysis was carried out on the zinc-bearing dust sludge (Figure 1), which revealed that the volume-weighted average particle size of the sludge sample was $76.80 \mu \mathrm{m}$. X-ray diffraction (XRD) analysis results are shown in Figure 2, whence it can be seen that the main zinc-bearing minerals present were simonkolleite $\left(\mathrm{Zn}_{5}(\mathrm{OH})_{8} \mathrm{Cl}_{2}\right)$, zincite $(\mathrm{ZnO})$, sphalerite $(\mathrm{ZnS})$, and franklinite $\left(\mathrm{ZnFe}_{2} \mathrm{O}_{4}\right)$. In addition, the main iron-bearing minerals present were magnetite and hematite, and small amounts of gypsum and quartz were also present. The type of $\mathrm{X}$-ray used in $\mathrm{XRD}$ is $\mathrm{Cu} \mathrm{K} \alpha$ radiation with a wavelength of $0.154056 \mathrm{~nm}$.

\subsection{Main Reagents and Instruments Used}

The main reagents used in this study were choline chloride $\left(\mathrm{HOC}_{2} \mathrm{H}_{4} \mathrm{~N}\left(\mathrm{CH}_{3}\right)_{3} \mathrm{Cl}\right)$ and urea $\left(\mathrm{NH}_{2} \mathrm{CONH}_{2}\right)$. The main instruments used were a vacuum drying oven (DZF6020, Shanghai Jinghong Laboratory Instrument Co., Ltd., Shanghai, China), and an X-ray fluorescence spectrometer (XRF) (RIGAKU ZSX Priums, PANalytical, Tokyo, Japan). 


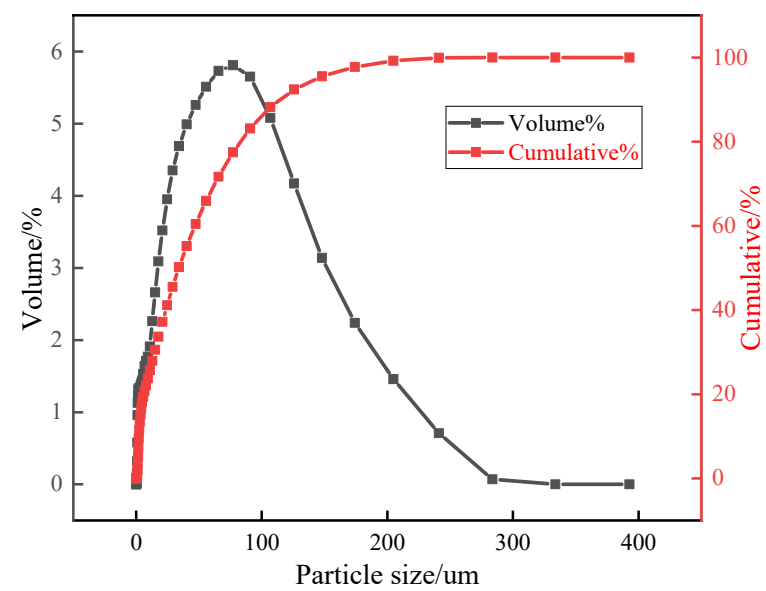

Figure 1. Laser particle size analysis of the zinc-bearing dust sludge.

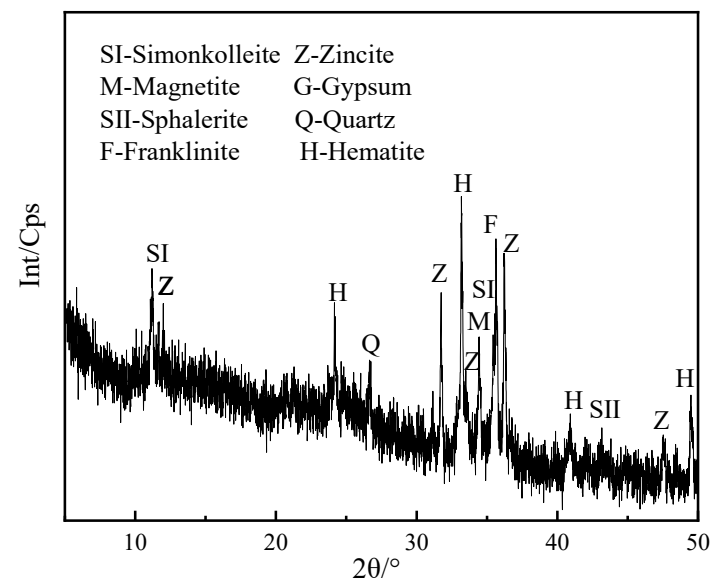

Figure 2. XRD analysis of the zinc-bearing dust sludge.

\subsection{Preparation of Deep Eutectic Solvent}

To prepare the ChCl-urea DES, some choline chloride and urea were placed in a vacuum drying oven for $840 \mathrm{~min}$ under a temperature and pressure of $80^{\circ} \mathrm{C}$ and $-0.05 \mathrm{MPa}$, respectively, before being mixed thoroughly in a molar ratio of $1: 2$, placed into a $1 \mathrm{~L}$ beaker, and heated in an oil bath at $80{ }^{\circ} \mathrm{C}$ to obtain a uniform transparent solution which was sealed for later use [18]. The prepared ChCl-urea DES is shown in Figure 3. It can be seen from the figure that this $\mathrm{ChCl}$-urea DES is a colorless and transparent liquid with a viscosity greater than water. At $80^{\circ} \mathrm{C}$, the viscosity of the DES was $20 \mathrm{mPa} \cdot \mathrm{s}$.

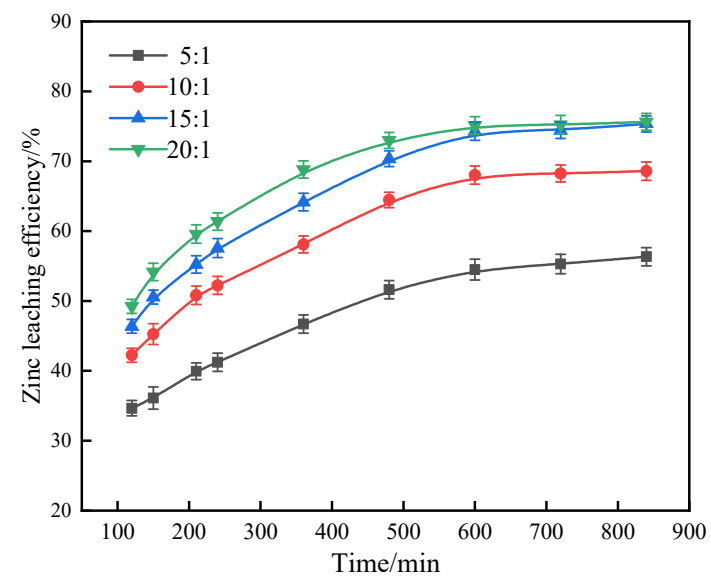

Figure 3. Effect of liquid-solid ratio on the zinc leaching efficiency. 


\subsection{Experimental Method}

In each experiment, $10,000 \mathrm{~g}$ of a sludge sample was added to the prepared $\mathrm{ChCl}$-urea DES in a $300 \mathrm{~mL}$ conical flask at a given ratio of liquid at 5:1,10:1,15:1, or 20:1 volume to solid mass (liquid-solid ratio). A magnetic rotor was added to the prepared conical flask, it was placed on the magnetic stirrer and heated in a water bath at 60, 70, 80, 90, and $100{ }^{\circ} \mathrm{C}$. The leaching temperature and stirring speed were controlled using the six-link asynchronous electric magnetic stirrer. The experiment ended after a certain reaction time, the filter residue and filtrate were separated using the vacuum filter extractor and the filter residue was dried and weighed, and the volume of the filtrate was measured and ascertained the zinc contention the filtrate via atomic absorption. Each single factor experiment was repeated three times, and if the experimental data was normal, the final leaching efficiency was obtained by taking the average of the three results, which made the experimental data more reliable. The zinc leaching efficiency, $\varepsilon$, was calculated as follows:

$$
\varepsilon=\frac{\mathrm{V}_{1} \times \mathrm{c}_{1}}{\mathrm{~m}_{0} \times \mathrm{x}_{0}} \times 100 \%
$$

where $\mathrm{m}_{0}$ is the mass of the zinc-bearing sludge dust sample $(\mathrm{g}), \mathrm{x}_{0}$ is zinc content of the zinc-bearing dust sludge sample (\%), $\mathrm{V}_{1}$ is the volume of leachate (L), and $\mathrm{c}_{1}$ is the concentration of zinc in the leachate $(\mathrm{g} / \mathrm{L})$.

\section{Results and Discussion}

\subsection{Effect of Different Conditions on the Zinc Leaching Efficiency}

3.1.1. Liquid-Solid Ratio

The liquid-solid ratio was varied at different leaching times while keeping the leaching temperature and stirring speed constant at $70{ }^{\circ} \mathrm{C}$ and $400 \mathrm{rpm}$, respectively (Figure 3). The results show that for leaching times $<600 \mathrm{~min}$, the zinc leaching efficiency is greatly affected by the liquid-solid ratio, whereas for leaching times $>600 \mathrm{~min}$, the leaching efficiency increases slowly with time before plateauing at $600 \mathrm{~min}$. The main reason for this is that increasing the liquid-solid ratio leads to a reduction in the concentration of zinc-bearing dust sludge in DESs and in the concentration of $\left[\mathrm{ZnOCl}\left(\mathrm{NH}_{2} \mathrm{CONH}_{2}\right)_{2}\right]^{-}$, which increases the rate of mass transfer [19] between the sludge and the DES, thereby increasing the leaching efficiency. With continuous leaching, the zinc content in the sludge gradually decreases, and the solid-liquid reaction rate tends towards equilibrium. At a leaching time of $600 \mathrm{~min}$, the leaching efficiency increased by only $0.82 \%$ (from $74.30 \%$ to $75.12 \%$ ) when the liquid-solid ratio was increased from 15:1 to 20:1. Because of the relatively high viscosity of this DES, a large liquid-solid ratio will cause certain difficulties for subsequent liquid-solid separation, and at the same time, considering the cost of the experiment, therefore, the liquid-solid ratio in subsequent experiments was fixed at 15:1.

\subsubsection{Leaching Temperature}

The leaching temperature was varied at different leaching times while keeping the liquid-solid ratio and stirring speed constant at 15:1 and $400 \mathrm{rpm}$, respectively (Figure 4). The results show that the zinc leaching effect is heavily temperature-dependent, as increasing the temperature can reduce the viscosity of the $\mathrm{ChCl}$-urea DES and increase the reaction rate. However, as the temperature continues to increase, the leaching efficiency plateaus. Figure 4 shows that, at a leaching time of $600 \mathrm{~min}$, the zinc extraction efficiencies at $90^{\circ} \mathrm{C}$ and $100{ }^{\circ} \mathrm{C}$ (which represents the maximum possible temperature of the water bath used) were $86.87 \%$ and $87.84 \%$, respectively. Considering that the zinc leaching efficiency was not very different under the two temperature conditions, the leaching temperature in subsequent experiments was fixed at $90^{\circ} \mathrm{C}$. 


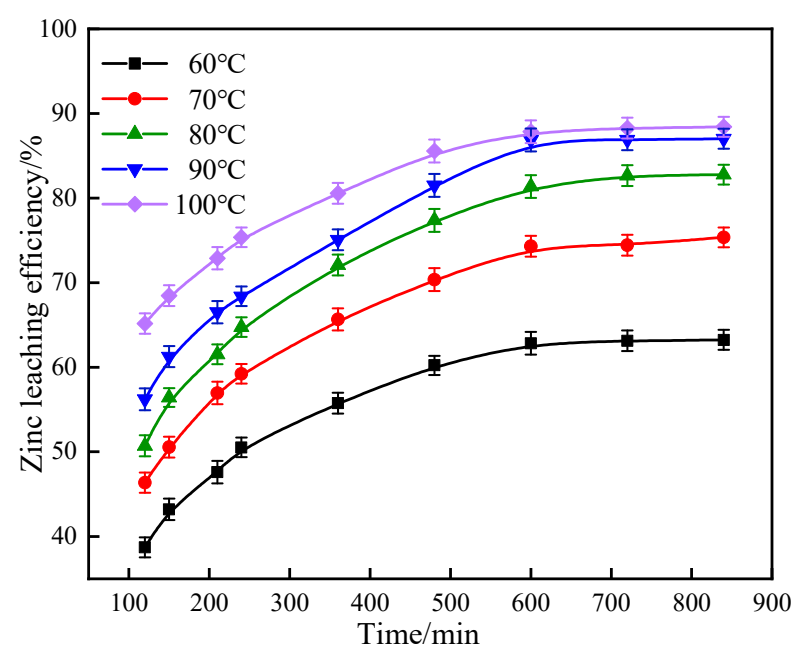

Figure 4. Effect of leaching temperature on zinc leaching efficiency.

\subsubsection{Stirring Speed}

Under certain conditions, increasing the stirring speed of the mixture can increase the reaction efficiency of the leaching agent by increasing the solid-liquid contact area and reducing the thickness of the diffusion layer. However, under leaching temperature and time conditions of $90^{\circ} \mathrm{C}$ and $600 \mathrm{~min}$, respectively, Figure 5 shows that the stirring speed had a relatively small effect on the leaching efficiency. Above $400 \mathrm{rpm}$, however, the zinc leaching efficiency hardly changed. Given that excessively fast stirring can cause the leaching liquid to splash, which is undesirable, $400 \mathrm{rpm}$ was chosen as the optimum stirring speed.

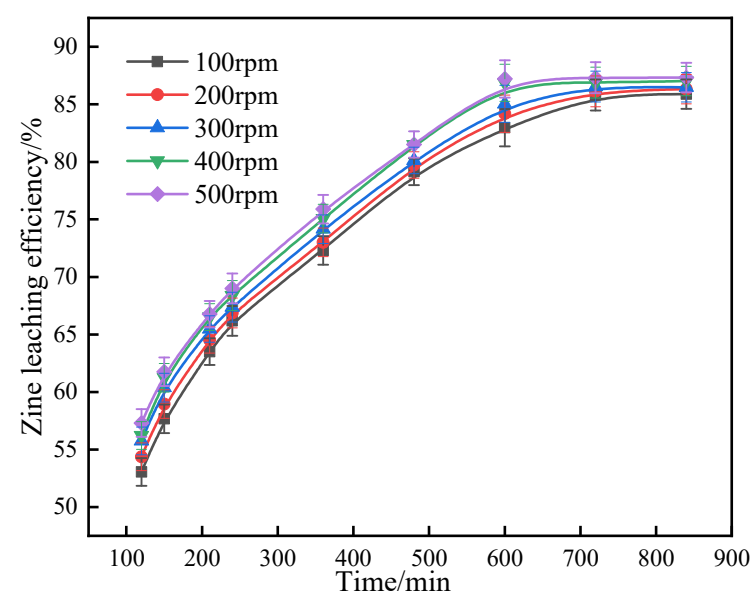

Figure 5. Effect of stirring speed on the zinc leaching efficiency.

\subsubsection{Leaching Time}

As zinc leaching is an equilibrium process, increasing the leaching time will only improve the leaching efficiency as long as equilibrium has not yet been reached. In this study, the leaching time was varied from $120-840 \mathrm{~min}$. Figures $3-5$ show that, once the leaching time increases to $600 \mathrm{~min}$, the zinc leaching efficiency does not change significantly thereafter, indicating that this time corresponds to diffusion equilibrium. Hence, the optimum leaching time was selected as $600 \mathrm{~min}$.

\subsection{Response Surface Model of Zinc Oxide Leaching in Zinc-Bearing Dust Sludge}

The orthogonal experiment was designed so that the liquid-solid ratio, leaching temperature, leaching time, and stirring speed were used as independent variables, and zinc leaching efficiency was used as the evaluation index, and the factor values and level 
codes were obtained (Table 2). The Stat-Ease Design-Expert 12.0 software package was used to design 29 sets of leaching experiments, in which the zinc leaching efficiencies obtained under different conditions are shown in Table 3.

Table 2. Experimental factor values and level coding.

\begin{tabular}{ccccc}
\hline & & \multicolumn{3}{c}{ Level Coding } \\
\cline { 3 - 5 } Factor & Code & $\mathbf{- 1}$ & $\mathbf{0}$ & $\mathbf{1}$ \\
\hline Liquid-solid ratio $(\mathrm{mL} / \mathrm{g})$ & $\mathrm{X}_{1}$ & $10: 1$ & $15: 1$ & $20: 1$ \\
Time $(\mathrm{min})$ & $\mathrm{X}_{2}$ & 80 & 90 & 100 \\
Temperature $\left({ }^{\circ} \mathrm{C}\right)$ & $\mathrm{X}_{3}$ & 480 & 600 & 720 \\
Stirring speed $(\mathrm{rpm})$ & $\mathrm{X}_{4}$ & 300 & 400 & 500 \\
\hline
\end{tabular}

Table 3. Experimental design and results.

\begin{tabular}{|c|c|c|c|c|c|}
\hline \multirow{2}{*}{ Number } & \multicolumn{4}{|c|}{ Factor } & \multirow{2}{*}{$\begin{array}{c}\text { Zinc Leaching Efficiency } \\
\text { Y (\%) }\end{array}$} \\
\hline & $X_{1}(\mathrm{~mL} / \mathrm{g})$ & $X_{2}(\min )$ & $\mathrm{X}_{3}\left({ }^{\circ} \mathrm{C}\right)$ & $\mathrm{X}_{4}(\mathrm{rpm})$ & \\
\hline 1 & 0 & 0 & -1 & 1 & 82.50 \\
\hline 2 & 0 & -1 & 0 & 1 & 81.51 \\
\hline 3 & 0 & 1 & 0 & 1 & 87.31 \\
\hline 4 & 0 & 1 & -1 & 0 & 82.65 \\
\hline 5 & -1 & 0 & 0 & 1 & 83.44 \\
\hline 6 & 1 & 0 & 0 & -1 & 86.50 \\
\hline 7 & 1 & 0 & 1 & 0 & 87.58 \\
\hline 8 & 0 & 0 & 0 & 0 & 86.87 \\
\hline 9 & 1 & 0 & -1 & 0 & 83.85 \\
\hline 10 & -1 & -1 & 0 & 0 & 78.34 \\
\hline 11 & 0 & -1 & -1 & 0 & 77.37 \\
\hline 12 & -1 & 1 & 0 & 0 & 84.12 \\
\hline 13 & 1 & 0 & 0 & 1 & 87.20 \\
\hline 14 & 0 & 0 & 0 & 0 & 87.47 \\
\hline 15 & 0 & 0 & -1 & -1 & 81.02 \\
\hline 16 & 0 & 0 & 1 & 1 & 87.30 \\
\hline 17 & 1 & -1 & 0 & 0 & 82.17 \\
\hline 18 & 0 & 0 & 0 & 0 & 85.90 \\
\hline 19 & 0 & 0 & 1 & -1 & 86.00 \\
\hline 20 & 0 & -1 & 0 & -1 & 80.13 \\
\hline 21 & -1 & 0 & -1 & 0 & 80.30 \\
\hline 22 & -1 & 0 & 0 & -1 & 82.26 \\
\hline 23 & 0 & 1 & 0 & -1 & 86.54 \\
\hline 24 & 0 & 1 & 1 & 0 & 88.26 \\
\hline 25 & 1 & 1 & 0 & 0 & 87.80 \\
\hline 26 & 0 & -1 & 1 & 0 & 85.57 \\
\hline 27 & 0 & 0 & 0 & 0 & 86.32 \\
\hline 28 & 0 & 0 & 0 & 0 & 86.47 \\
\hline 29 & -1 & 0 & 1 & 0 & 83.53 \\
\hline
\end{tabular}

The Stat-Ease Design-Expert 12.0 software package was used to analyze the sample data and the repeatedly binomial regression model of zinc leaching efficiency was obtained (Equation (2)).

$$
\begin{gathered}
\mathrm{Y}=86.61+1.93 \mathrm{~A}+2.63 \mathrm{~B}+2.55 \mathrm{C}+0.5675 \mathrm{D}-0.0375 \mathrm{AB}+0.1250 \mathrm{AC}-0.1200 \mathrm{AD}-0.6475 \mathrm{BC}- \\
0.1525 \mathrm{BD}-0.0450 \mathrm{CD}-1.30 \mathrm{~A} 2-1.97 \mathrm{~B} 2-1.45 \mathrm{C} 2-0.7247 \mathrm{D} 2
\end{gathered}
$$

where $\mathrm{A}$ is the liquid-solid ratio, $\mathrm{B}$ is the leaching time, $\mathrm{C}$ is the leaching temperature, and $\mathrm{D}$ is the stirring speed.

Equation (2) was used in the analysis of the variance of the zinc leaching efficiency model. In the analysis results (Table 4 ), if $p<0.0001$, the effect was highly significant, if $p \leq 0.0500$, it was significant, and if $p>0.1000$, it was not significant. The F-value of 
the model (Table 4) was 22.47, $p<0.0001$, indicating that this regression equation was highly significant, and there was a non-linear relationship between each factor and the leaching efficiency of the response value. The lack of fit was 2.72 and its $p$-value was 0.1735 , which was not significant, indicating that the regression equation fitted well. From the $p$-value and the coefficients of Equation (2), it can be judged that the order of the significant influence of the factors on zinc leaching efficiency was leaching time $>$ leaching temperature $>$ liquid-solid ratio $>$ stirring speed.

Table 4. Variance analysis of zinc leaching efficiency model.

\begin{tabular}{cccccc}
\hline Source & Sum of Squares & df & Mean Square & F-Value & $p$-Value \\
\hline Model & 248.10 & 14 & 17.72 & 22.47 & $<0.0001$ \\
A-Liquid-solid & 44.51 & 1 & 44.51 & 56.44 & $<0.0001$ \\
ratio & 83.16 & 1 & 83.16 & 105.45 & $<0.0001$ \\
B-Time & 77.78 & 1 & 77.78 & 98.62 & $<0.0001$ \\
C-Temperature & 3.86 & 1 & 3.86 & 4.90 & 0.0440 \\
D-Stirring speed & 0.0056 & 1 & 0.0056 & 0.0071 & 0.9339 \\
AB & 0.0625 & 1 & 0.0625 & 0.0793 & 0.7824 \\
AC & 0.0576 & 1 & 0.0576 & 0.0730 & 0.7909 \\
AD & 1.68 & 1 & 1.68 & 2.13 & 0.1668 \\
BC & 0.0930 & 1 & 0.0930 & 0.1180 & 0.7364 \\
BD & 0.0081 & 1 & 0.0081 & 0.0103 & 0.9207 \\
CD & 11.00 & 1 & 11.00 & 13.95 & 0.0022 \\
A & 25.10 & 1 & 25.10 & 31.83 & $<0.0001$ \\
B $^{2}$ & 13.58 & 1 & 13.58 & 17.23 & 0.0010 \\
C $^{2}$ & 3.41 & 1 & 3.41 & 4.32 & 0.0566 \\
D $^{2}$ & 11.04 & 14 & 0.7886 & & \\
Residual & 9.63 & 10 & 0.9625 & 2.72 & 0.1735 \\
Lack of Fit & 1.41 & 4 & 0.3537 & & \\
Pure Error & & & & &
\end{tabular}

Response surface of the influence of various factors on zinc leaching efficiency were shown in Figure 6.
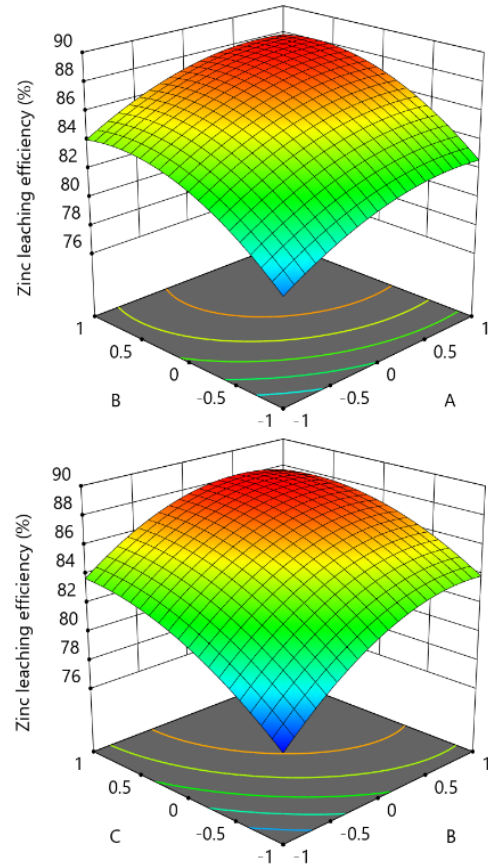
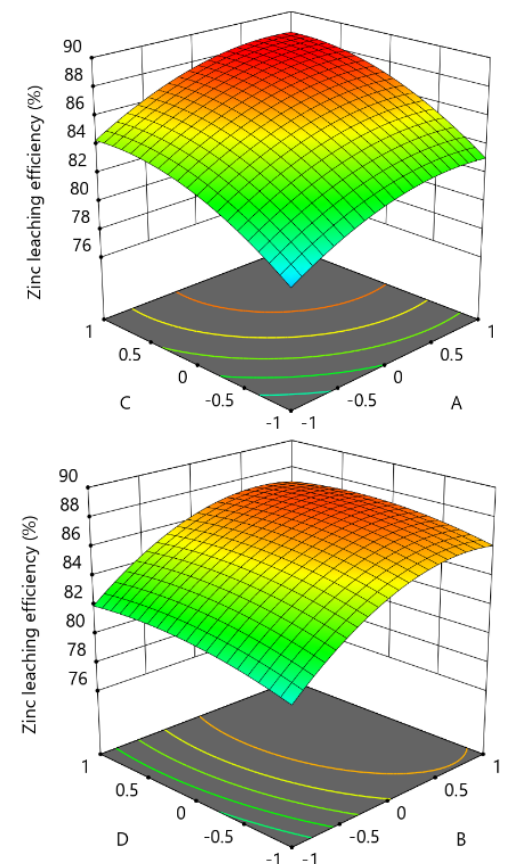
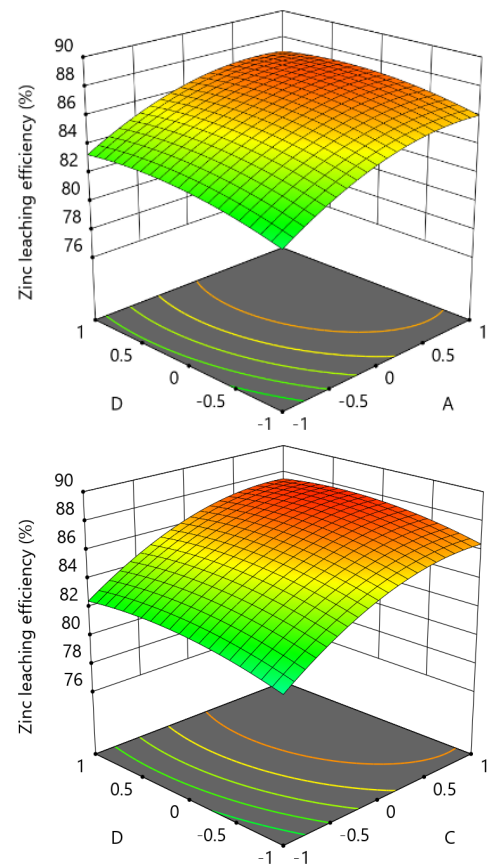

Figure 6. Response surface of the influence of various factors on zinc leaching efficiency. 
To verify the accuracy of the model, three sets of experiments were carried out under different experimental conditions. The comparison between the zinc leaching efficiency values and the values calculated by the multiple regression fitting is shown in Table 5. Under different conditions, the deviation between the experimental value and the calculated value of multiple regression fitting was less than $0.50 \%$. Therefore, the model can truly reflect the effects of various factors on zinc leaching efficiency.

Table 5. Comparison of mental values and calculated values.

\begin{tabular}{|c|c|c|c|c|c|}
\hline Liquid-Solid Ratio (mL/g) & Time (min) & Temperature $\left({ }^{\circ} \mathrm{C}\right)$ & Stirring Speed (rpm) & Experimental Value (\%) & Calculated Values (\%) \\
\hline $10: 1$ & 720 & 80 & 500 & 82.12 & 82.48 \\
\hline $20: 1$ & 480 & 100 & 300 & 85.25 & 85.04 \\
\hline $15: 1$ & 480 & 100 & 300 & 83.96 & 84.13 \\
\hline
\end{tabular}

\subsection{Characterization of Zinc-Bearing Dust Sludge before and after Leaching}

To study the changes in the morphology and surface composition of the raw material and leaching residue, the samples were analyzed by a scanning electron microscope (SEM) before and after leaching. The results are shown in Figure 7a-c, whence it can be seen that the surface of the sludge before leaching was rough and irregular, with many relatively dense and bright colored flocs and strips present; however, after leaching, many holes and obvious gullies appeared, which is likely due to the dissolution of zinc oxide.

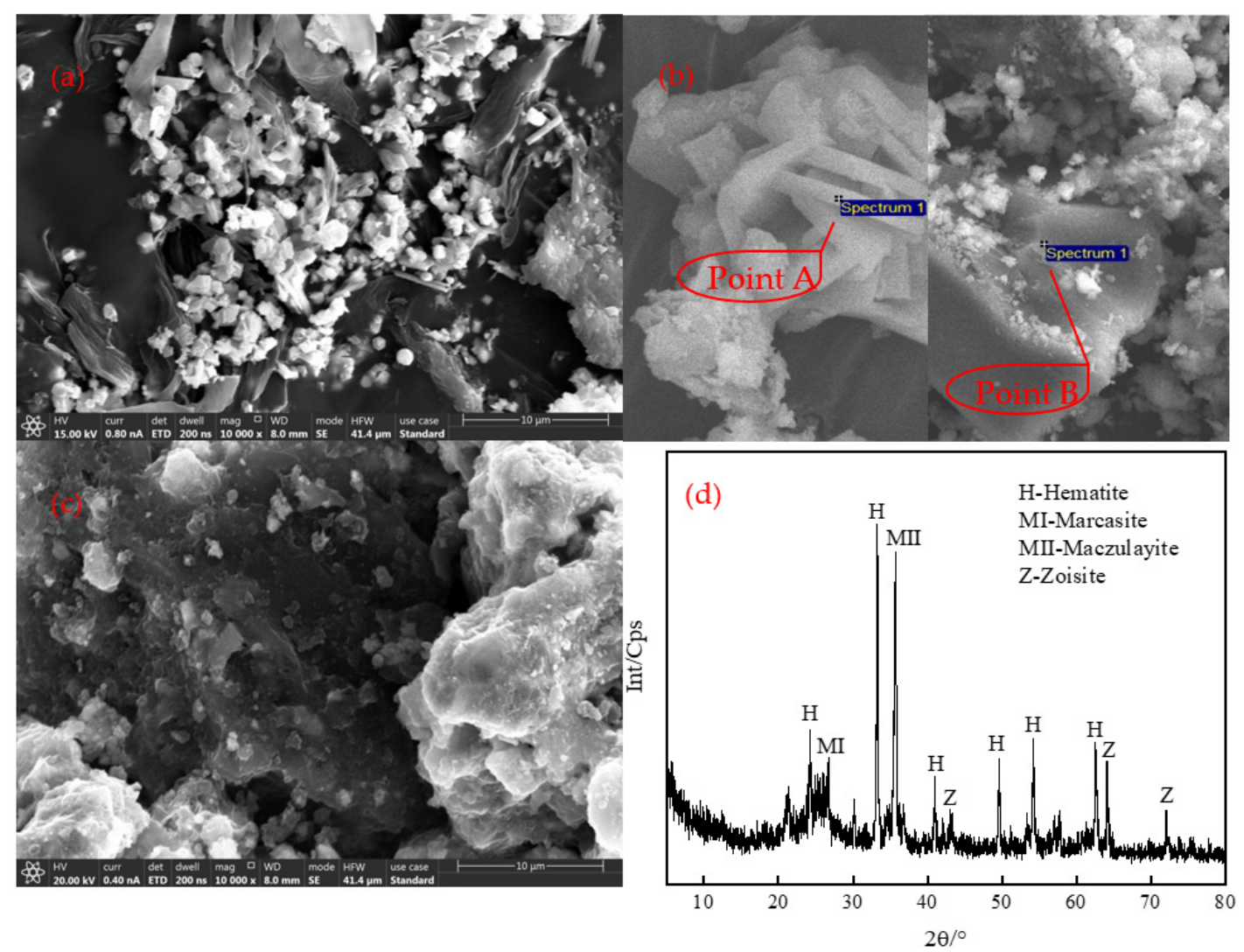

Figure 7. SEM images (a), (b) before and (c) after leaching, and (d) XRD patterns after leaching.

The point scanning results of the X-ray spectrum analysis (Figure 7) show that the zinc content in the dense flocks and striped parts of the sample was higher before leaching (Figure $7 \mathrm{~b}$, point $\mathrm{A}$ ), while the darker parts of the sample surface consist of carbon and oxygen (Figure $7 \mathrm{~b}$, point $\mathrm{B}$ ). The large reduction in flocs and strips after leaching also serves as an indicator that zinc has been leached. The XRD pattern after leaching (Figure 7d) showed that the main minerals present in the leaching residue were hematite, marcasite, 
and zoisite, and that the diffraction intensity of zinc-containing minerals cannot be detected. The type of X-ray used in XRD was $\mathrm{Cu} \mathrm{K} \alpha$ radiation with a wavelength of $0.154056 \mathrm{~nm}$.

Table 6 shows the XRF analysis results for the leaching residue under optimal leaching conditions, whence it can be seen that the $\mathrm{ZnO}$ content of the samples before and after leaching decreased from $12.98 \%$ to $1.86 \%$, while that of $\mathrm{Fe}_{2} \mathrm{O}_{3}$ decreased from $35.11 \%$ to $27.22 \%$. Furthermore, the leaching efficiency was $20.01 \%$, and the content of other oxides did not change significantly. These results indicate that the ChCl-urea DES indeed possesses excellent $\mathrm{ZnO}$-dissolving properties.

Table 6. XRF analysis of leaching residue (\%).

\begin{tabular}{ccccccccc}
\hline $\mathrm{TFe}$ & $\mathrm{ZnO}$ & $\mathrm{SiO}_{2}$ & $\mathrm{Cl}$ & $\mathrm{Al}_{2} \mathrm{O}_{3}$ & $\mathrm{CaO}$ & $\mathrm{PbO}$ & $\mathrm{MgO}$ & $\mathrm{K}_{2} \mathrm{O}$ \\
\hline 27.22 & 1.86 & 10.18 & 2.28 & 6.17 & 3.54 & 1.50 & 1.51 & 0.16 \\
\hline
\end{tabular}

\subsection{Reaction Mechanism}

The formation of the ChCl-urea DES with a molar ratio of 1:2 is as follows [20]:

$$
\mathrm{HOC}_{2} \mathrm{H}_{4} \mathrm{~N}\left(\mathrm{CH}_{3}\right)_{3} \mathrm{Cl}(a q)+2\left(\mathrm{NH}_{2} \mathrm{CONH}_{2}\right)(a q)=\left[\mathrm{HOC}_{2} \mathrm{H}_{4} \mathrm{~N}\left(\mathrm{CH}_{3}\right)_{3}\right]^{+}(a q)+\left(\mathrm{NH}_{2} \mathrm{CONH}_{2}\right)_{2}[\mathrm{Cl}]^{-}(a q)
$$

In this process, the choline chloride and urea molecules act as hydrogen bond acceptors and hydrogen bond donors, respectively, interacting to generate hydrogen bond forces, which destroys the lattice structure of $\mathrm{ChCl}$ and urea, and reduces the lattice energy, thereby lowering the melting point of $\mathrm{ChCl}$ and urea, and forming a liquid mixture [21]. The BIOVIA Materials Studio software package was used to simulate the microstructure

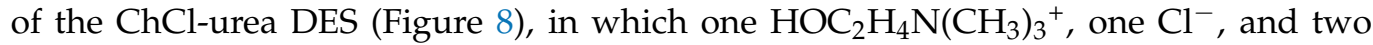
$\mathrm{NH}_{2} \mathrm{CONH}_{2}$ molecules are combined with each other through hydrogen bonds, with the $\mathrm{Cl}^{-}$forming a hydrogen bond with the $-\mathrm{NH}$ in $\mathrm{NH}_{2} \mathrm{CONH}_{2}$, and the $\mathrm{O}$ in urea forming a hydrogen bond with the $-\mathrm{CH}$ in $\mathrm{HOC}_{2} \mathrm{H}_{4} \mathrm{~N}\left(\mathrm{CH}_{3}\right)_{3}{ }^{+}$.

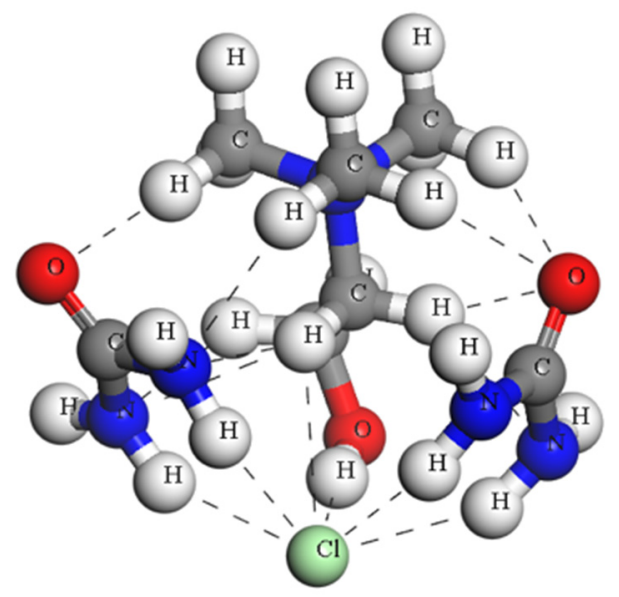

Figure 8. Molecular structure diagram of the ChCl-urea DES.

In the leaching process, the $\mathrm{ChCl}$-urea $\mathrm{DES}$ dissolved the $\mathrm{ZnO}$ in the zinc-bearing dust sludge to form the complex $\left[\mathrm{ZnOCl}\left(\mathrm{NH}_{2} \mathrm{CONH}_{2}\right)_{2}\right]^{-}$, as follows:

$$
\mathrm{ZnO}(s)+2\left(\mathrm{NH}_{2} \mathrm{CONH}_{2}\right)(a q)+[\mathrm{Cl}]^{-}(a q)=\left[\mathrm{ZnOCl}\left(\mathrm{NH}_{2} \mathrm{CONH}_{2}\right)_{2}\right]^{-}(a q)
$$

The Materials Studio-simulated microstructure of the $\left[\mathrm{ZnOCl}\left(\mathrm{NH}_{2} \mathrm{CONH}_{2}\right)_{2}\right]^{-}$is shown in Figure 9, shows that $\mathrm{ChCl}$-urea decomposed in the process of interacting with $\mathrm{ZnO}$, during which the choline cations formed multiple hydrogen bonds with the oxygen atoms on the surface of $\mathrm{ZnO}$, while the $\mathrm{Cl}^{-}$and urea formed chemical bonds with the Zn atoms. 


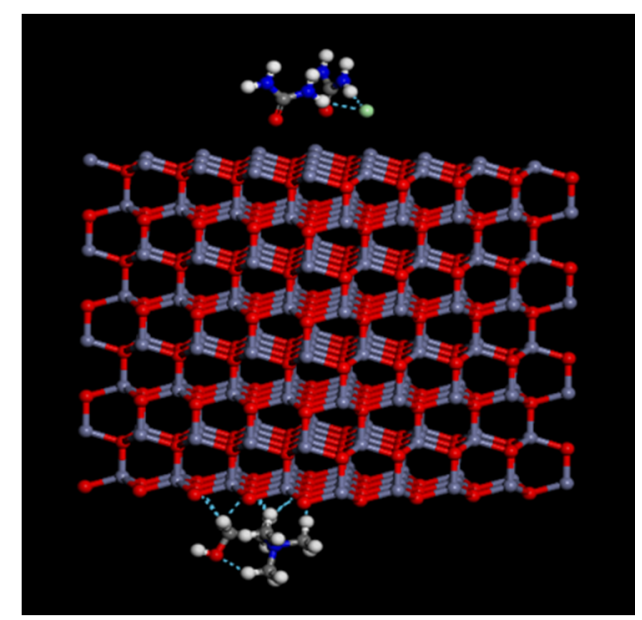

Figure 9. Molecular structure diagram of the reaction product between $\mathrm{ZnO}$ and the ChCl-urea DES.

\subsection{Leaching Kinetic Analysis}

To determine the mechanism of the leaching reaction and maximize the efficiency of the leaching process, the reaction kinetics was modeled. The reaction of $\mathrm{ZnO}$ with the ChCl-urea DES is a heterogeneous (solid-liquid reaction), and the reactants (powder particles) were regarded as uniform spheres; hence, the most used type of model for such systems, the nuclear shrinkage model, was adopted. During the leaching process, the free urea reacts with $\mathrm{Cl}^{-}$and zinc oxide in the zinc-bearing dust sludge, and the product $\left[\mathrm{ZnOCl}\left(\mathrm{NH}_{2} \mathrm{CONH}_{2}\right)_{2}\right]^{-}$dissolved in the leaching agent. Therefore, the leaching process is produced without a solid product layer reaction. Due to the high concentration of $\mathrm{ChCl}$-urea DES, the consumption of urea and $\mathrm{Cl}^{-}$during the reaction can be ignored, and the concentration of the extractant can be regarded as unchanged. Therefore, the integrated rate equation is shown below [22]:

$$
1-(1-\mathrm{x})^{\frac{1}{3}}=\frac{\mathrm{bk}^{\prime} \mathrm{C}_{0}}{\mathrm{a} \rho \mathrm{r}_{0}} \mathrm{t}=\mathrm{kt}
$$

where $x$ is the leaching efficiency of $\mathrm{ZnO}$ in the dust sludge at time $t ; \mathrm{k}^{\prime}$ is the apparent rate constant $\left(\mathrm{min}^{-1}\right), \mathrm{t}$ is the reaction time $(\mathrm{min})$, and $\mathrm{C}_{0}$ and $\rho$ are the initial concentration and molar density (both in mol/L) of the ChCl-urea DES, respectively, $\mathrm{r}_{0}$ is the initial radius of the reaction particles of the zinc-bearing dust sludge sample $(\mathrm{m}) ; \mathrm{k}$ is the kinetic constant calculated $(\mathrm{m} / \mathrm{min})$, and $\mathrm{a}$ and $\mathrm{b}$ are the stoichiometric coefficients of $\mathrm{ZnO}$ and $\left(\mathrm{NH}_{2} \mathrm{CONH}\right)_{2}[\mathrm{Cl}]^{-}$, respectively.

\subsubsection{Determination of the Kinetic Model}

Using the data from Section 3.1, the kinetic constant $k$ and correlation coefficient of the leaching reaction were calculated using Equation (5), with the results shown in Table 7.

The values calculated using the leaching kinetic model at different values of the liquid-solid ratio, leaching temperature, and stirring speed are shown in Figure 10, which confirms that, according to Equation (5), the zinc leaching efficiency is linearly correlated with all three variables, further indicating the validity of this model. 
Table 7. Kinetic constants and correlation coefficients of reaction kinetic models under different conditions.

\begin{tabular}{|c|c|c|c|c|}
\hline \multirow{3}{*}{ Parameter } & \multicolumn{4}{|c|}{ Leaching Reaction Kinetic Model } \\
\hline & \multicolumn{4}{|c|}{$1-(1-x)^{\frac{1}{3}}=\frac{\mathbf{b k}^{\prime} \mathbf{C}_{0}}{\mathbf{a} \rho \mathbf{r}_{0}} \mathbf{t}=\mathbf{k t}$} \\
\hline & $\mathbf{x}$ & $\mathbf{k}^{\prime}(\mathrm{m} / \mathrm{min})$ & $k\left(\min ^{-1}\right)$ & $\mathbf{R}^{2}$ \\
\hline \multicolumn{5}{|c|}{ Liquid-solid ratio/(mL/g) } \\
\hline $5: 1$ & $54.49 \%$ & $1.61 \times 10^{-8}$ & $4.18 \times 10^{-4}$ & 0.9924 \\
\hline $10: 1$ & $68.03 \%$ & $2.39 \times 10^{-8}$ & $4.97 \times 10^{-4}$ & 0.9856 \\
\hline $15: 1$ & $74.30 \%$ & $2.78 \times 10^{-8}$ & $4.98 \times 10^{-4}$ & 0.9909 \\
\hline $20: 1$ & $75.12 \%$ & $\begin{array}{c}3.63 \times 10^{-8} \\
\mathrm{~T} /{ }^{\circ} \mathrm{C}\end{array}$ & $4.36 \times 10^{-4}$ & 0.9882 \\
\hline 60 & $62.83 \%$ & $1.21 \times 10^{-6}$ & $1.57 \times 10^{-2}$ & 0.9788 \\
\hline 70 & $74.30 \%$ & $1.64 \times 10^{-6}$ & $2.13 \times 10^{-2}$ & 0.9784 \\
\hline 80 & $81.37 \%$ & $2.03 \times 10^{-6}$ & $2.45 \times 10^{-2}$ & 0.9802 \\
\hline 90 & $86.87 \%$ & $2.30 \times 10^{-6}$ & $2.99 \times 10^{-2}$ & 0.9957 \\
\hline \multicolumn{5}{|c|}{ Stirring speed/rpm } \\
\hline 100 & $82.96 \%$ & $2.00 \times 10^{-6}$ & $4.53 \times 10^{-4}$ & 0.9967 \\
\hline 200 & $84.18 \%$ & $3.48 \times 10^{-6}$ & $4.46 \times 10^{-4}$ & 0.9934 \\
\hline 300 & $85.04 \%$ & $3.54 \times 10^{-6}$ & $4.79 \times 10^{-4}$ & 0.9952 \\
\hline 400 & $86.87 \%$ & $3.56 \times 10^{-6}$ & $4.82 \times 10^{-4}$ & 0.9947 \\
\hline 500 & $87.21 \%$ & $3.73 \times 10^{-6}$ & $4.97 \times 10^{-4}$ & 0.9956 \\
\hline
\end{tabular}

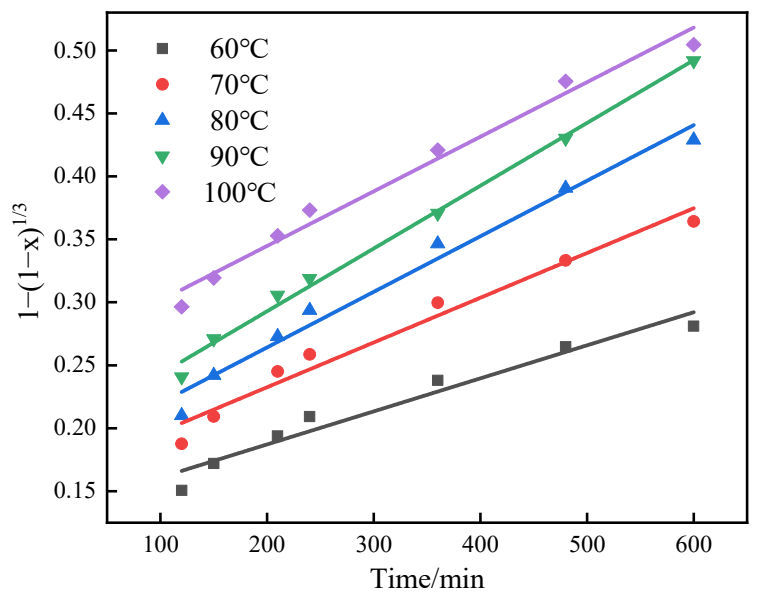

(a)

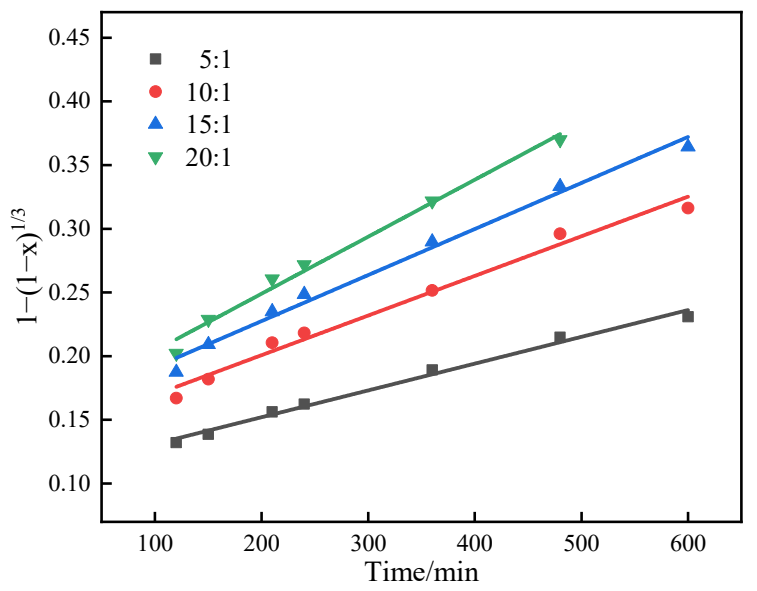

(b)

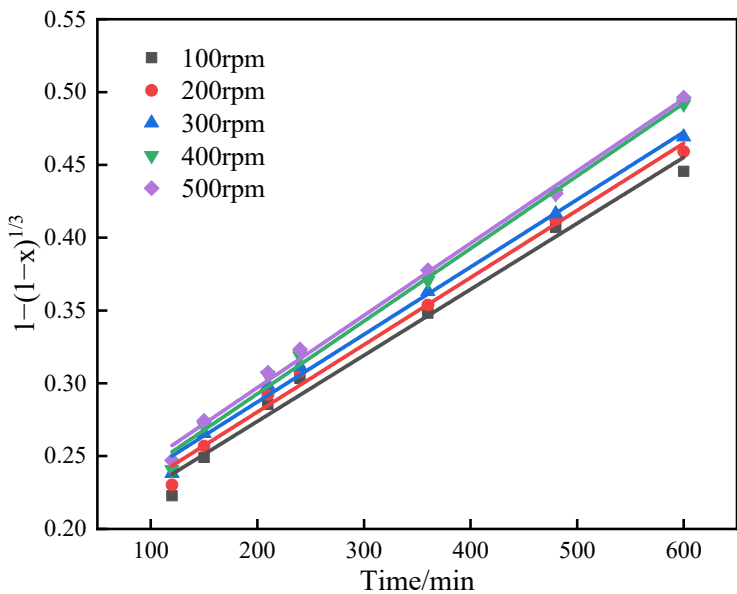

(c)

Figure 10. Kinetic reaction model under different leaching conditions: (a) leaching temperature, (b) liquid-solid ratio, and (c) stirring speed. 


\subsubsection{Determination of Apparent Activation Energy and Pre-Exponential Factor}

The reaction rate constant was modeled using the Arrhenius equation, as follows:

$$
\begin{gathered}
\mathrm{k}=\mathrm{Ae}^{-\mathrm{E}_{\mathrm{a}} / \mathrm{RT}} \\
\ln \mathrm{k}=\ln \mathrm{A}-\mathrm{E}_{\mathrm{a}} / \mathrm{R}
\end{gathered}
$$

where $\mathrm{A}$ is the pre-exponential factor, $\mathrm{R}$ is the universal gas constant $\left(=8.314 \mathrm{~J} \mathrm{~mol}^{-1} \mathrm{~K}^{-1}\right)$, $\mathrm{T}$ is the absolute temperature, and $\mathrm{E}_{\mathrm{a}}$ is the apparent activation energy of the reaction. Drawing from Equation (7), Figure 11 was obtained. The activation energy of the leaching reaction is $21.66 \mathrm{~kJ} / \mathrm{mol}$.

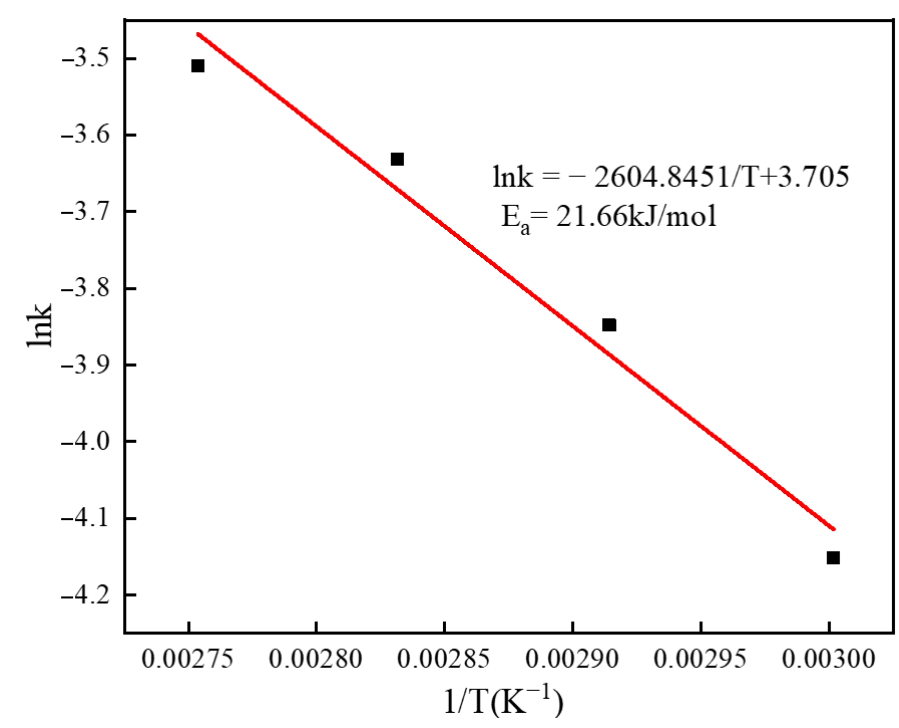

Figure 11. Linear fit of lnk vs $1 / \mathrm{T}$ for the leaching reaction kinetic model.

\subsubsection{Leaching Kinetic Equation}

To quantitatively describe the influence of the liquid-solid ratio and leaching temperature on the kinetics of zinc leaching, a semi-empirical equation was proposed, as follows [23,24]:

$$
1-(1-\mathrm{x})^{\frac{1}{3}}=\mathrm{kt}=\left[\mathrm{k}_{\mathrm{c}} \cdot \mathrm{N}^{\alpha} \cdot \mathrm{C}^{\beta} \cdot \mathrm{e}^{-\frac{\mathrm{Ea}}{\mathrm{RT}}}\right] \mathrm{t}
$$

where $\mathrm{k}_{\mathrm{c}}$ is the pre-exponential factor, and $\mathrm{N}, \mathrm{C}$, and $\mathrm{T}$ are the liquid-solid ratio, stirring speed, and leaching temperature, respectively. If $\mathrm{C}$ and $\mathrm{T}$ are constant, then $\mathrm{N}$ is the only variable, and Equation (8) may be simplified as:

$$
\begin{gathered}
1-(1-\mathrm{x})^{\frac{1}{3}}=\mathrm{kt}=\mathrm{k}_{\mathrm{c}} \cdot \mathrm{N}^{\alpha} \cdot \mathrm{t} \\
\frac{\mathrm{d}\left[1-(1-\mathrm{x})^{\frac{1}{3}}\right]}{\mathrm{dt}}=\mathrm{k}=\mathrm{k}_{\mathrm{c}} \cdot \mathrm{N}^{\alpha} \\
\ln \left[\frac{\mathrm{d}\left[1-(1-\mathrm{x})^{\frac{1}{3}}\right]}{\mathrm{dt}}\right]=\ln \mathrm{k}=\alpha \ln \mathrm{N}+\operatorname{lnk}_{\mathrm{c}}
\end{gathered}
$$

For Equation (11), if the values of $\ln \mathrm{K}$ and $\ln \mathrm{N}$ under different liquid-solid ratios are known, then $\operatorname{lnk}-\alpha$, which was $\ln \left[\frac{\mathrm{d}\left[1-(1-\mathrm{x})^{\frac{1}{3}}\right]}{\mathrm{dt}}\right]-\mathrm{LnN}$ correlation drawing, can be performed, as shown in Figure 12a. Linear fitting on the scatter points was performed to get the equation in the Figure $12 \mathrm{a}$, where $\alpha=0.55744, \operatorname{lnk}_{\mathrm{c}}=-9.37142$. In the same 
way, it can be calculated as $\beta=0.0551, \ln _{\mathrm{c}}=-7.95112$ in Equation (10), and Figure $12 \mathrm{~b}$ was obtained. From Figure 12, we can see that $E_{a} / R=-2604.8451, \ln _{\mathrm{c}}=3.705$, and $k_{c}$ $=-4.53918$ can be calculated by the average method. Hence, the kinetic equation of zinc leaching becomes:

$$
1-(1-\mathrm{x})^{\frac{1}{3}}=\left[-4.53918 \cdot \mathrm{N}^{0.55744} \cdot \mathrm{C}^{0.0551} \cdot \mathrm{e}^{-\frac{2604.8451}{\mathrm{~T}}}\right] \mathrm{t}
$$

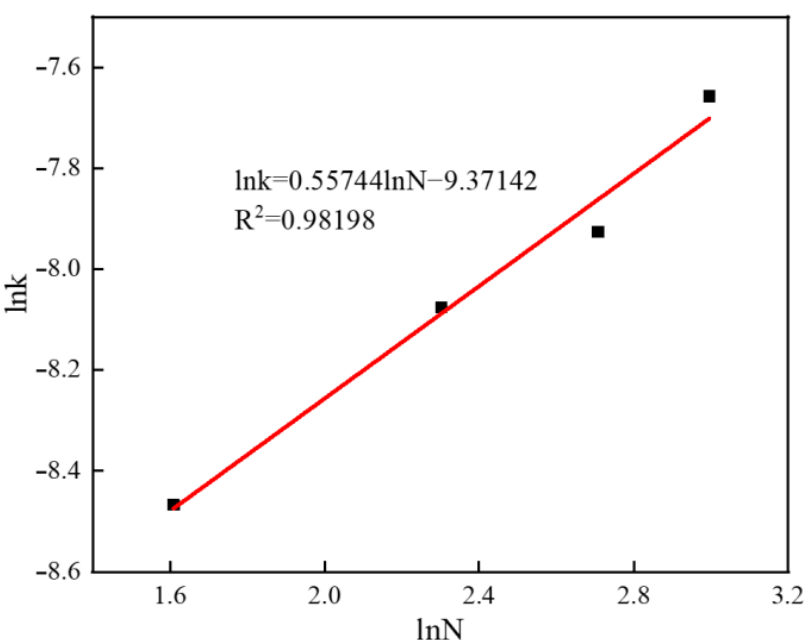

(a)

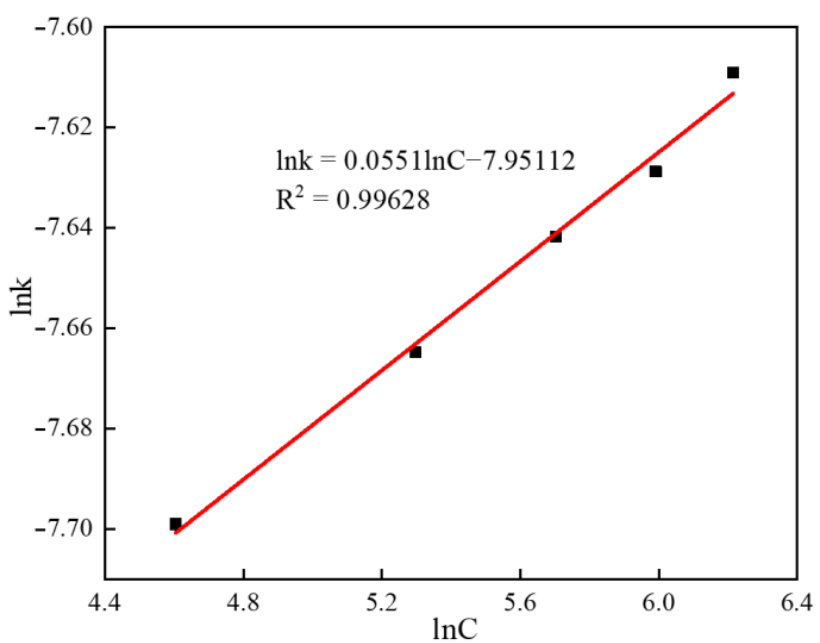

(b)

Figure 12. Change curve of lnk with different factors:(a) liquid-solid ratio; (b) Stirring speed.

\section{Conclusions}

(1) Based on the single-factor experimental results, the optimum process conditions for zinc leaching were determined to be a liquid-solid ratio of 15:1, a stirring speed of $400 \mathrm{rpm}$, a leaching temperature of $90^{\circ} \mathrm{C}$, and a leaching time of $600 \mathrm{~min}$, resulting in a leaching efficiency of $86.87 \%$.

(2) The leaching reaction involved the complexation of $\mathrm{Zn}$ with the ChCl-urea DES with $\mathrm{ZnO}$ to form $\left[\mathrm{ZnOCl}\left(\mathrm{NH}_{2} \mathrm{CONH}_{2}\right)_{2}\right]^{-}$.

(3) SEM analysis showed that the surface morphology of the zinc-bearing dust sludge samples changed noticeably before and after leaching, with the samples becoming darker and a large number of holes appearing on the surface. EDS and XRF analyses confirmed that the metallic zinc content was indeed reduced after leaching, while that of other elements did not change significantly.

(4) The kinetics of the leaching process was found to be consistent without solid product layer formation with the nuclear shrinkage model. Using this model, the activation energy was calculated to be $22.16 \mathrm{~kJ} / \mathrm{mol}$, and an empirical correlation was obtained to quantify the dependence of the leaching efficiency on the liquid-solid ratio, stirring speed, and leaching temperature.

Author Contributions: Designed the experiments, J.Z. and J.D.; performed the experiments, J.D.; analyzed the data, C.Y.; wrote the paper, J.D.; and improved the paper, F.N. All authors have read and agreed to the published version of the manuscript.

Funding: This work is financially supported by the National Natural Science Foundation of China (51904106, 51874135), Natural Science Foundation of Hebei Province (E2021209015), and Tangshan Basic Innovation Team (19130207C).

Data Availability Statement: Data available on request due to restrictions privacy. The data provided in this study can be obtained at the request of the corresponding author. As the data needs further research, the data is currently not publicly available. 
Conflicts of Interest: The authors declare no conflict of interest.

\section{References}

1. Shang, H.; Li, H.; Wei, R. Present situation and prospect of iron and steel dust and sludge. utilization technology. Iron Steel 2019, $54,9-17$.

2. Tao, M.; Zhang, X.; Wang, S.; Cao, W.; Jiang, Y. Life cycle assessment on lead-zinc ore mining and. beneficiation in China. J. Clean Prod. 2019, 237, 117833. [CrossRef]

3. Zhang, C.; Liu, H.; Wang, D.; Chen, Y.; Rui, Z.; Lou, D.; Wu, Y.; Jia, F.; Chen, Z.; Meng, X. A Preliminary Review on the Metallogeny of Pb-Zn Deposits in China. Acta Geol. Sin. 2015, 89, 1333-1358.

4. CNIA. Zinc Production by Province in 2020; Youse Jinshu; CNIA: Ottawa, ON, Canada, 2021; Volume 16.

5. Mehmet, K.; Kürşad, O.; Mehmet, Ş. Optimization of selective leaching of $\mathrm{Zn}$ from electricarc furnace steelmaking dust using response surface methodology. Trans. Nonferrous Met. Soc. China 2015, 25, 2753-2762.

6. Xie, Z.; Guo, Y.; Chen, F. Research status and prospect of comprehensive utilization of zinc-bearing dust in iron and steel plants. Sinter. Pelletizing 2016, 41, 53-56+61.

7. Liu, X.; Li, L.; Li, S.; Santosh, M.; Li, Y. Geochronology and Isotope Geochemistry of the Yingfang Pb-Zn-Ag Deposit: Implications for Large-Scale Metallogeny along the Northern Flank of the North China Craton. Minerals 2021, 11, 353. [CrossRef]

8. Yang, H.; Wu, Z. $\alpha-\mathrm{Fe}_{2} \mathrm{O}_{3} / \mathrm{ZnFe}_{2} \mathrm{O}_{4}$ Derived from Zinc-bearing Dust and Its Photocatalytic Degradation of Methylene Blue. Shandong Huagong 2019, 48, 240-242.

9. Gong, J.; Zhang, B.; Li, B. Recovery of iron from iron-containing dusts utilizing magnetizing roasting followed by magnetic separation. Min. Mag. 2010, 19, 64-66+72.

10. Pedram, A.; Parviz, P. Zinc Extraction from Zinc Plants Residue Using Selective Alkaline Leaching and Electrowinning. J. Inst. Eng. Ser. D 2015, 96, 179-187.

11. Dutra, A.J.B.; Paiva, P.R.P.; Tavares, L.M. Alkaline leaching of zinc from electric arc furnace steel dust. Miner. Eng. 2006, 19, 478-485. [CrossRef]

12. Piotr, P.; Stanisław, P.; Michał, S.; Ilona, N. Zinc Recovery from Steelmaking Dust by Hydrometallurgical Methods. Metals 2018, $8,547$.

13. Smith, E.L.; Abbott, A.P.; Ryder, K.S. Deep eutectic solvents (DESs) and their applications. J. Chem. Rev. 2014, 114, 11060-11082. [CrossRef] [PubMed]

14. Zhu, X.; Xu, C.; Tang, J.; Hua, Y.; Zang, Q.; Liu, H.; Wang, X.; Huang, M. Selective recovery of zinc from zinc oxide dust using choline chloride based deep eutectic solvents. Trans. Nonferrous Met. Soc. China 2019, 29, 2222-2228. [CrossRef]

15. Huang, K.; Shen, Y.; Wang, X.; Song, X.; Yuan, W.; Xie, J.; Wang, S.; Bai, J.; Wang, J. Choline-based deep eutectic solvent combined with EDTA-2Na as novel soil washing agent for lead removal in contaminated soil. Chemosphere 2021, 279, 130568. [CrossRef]

16. Santana-Mayor, Á.; Socas-Rodríguez, B.; Rodríguez-Ramos, R.; Herrera-Herrera, A.V.; Rodríguez-Delgado M, Á. Quality assessment of environmental water by a simple and fast non-ionic hydrophobic natural deep eutectic solvent-based extraction procedure combined with liquid chromatography tandem mass spectrometry for the determination of plastic migrants. Anal. Bioanal. Chem. 2021, 413, 1967-1981. [CrossRef] [PubMed]

17. Ju, D.; Yao, H.; Ma, H.; Mao, R.; Qiu, J.; Chen, C. Producing ZnO nano powder from rotary hearth furnace dust along with Pb removal. Inorg. Chem. Commun. 2021, 127, 108496. [CrossRef]

18. Abbott, A.P.; Capper, G.; Davies, D.L.; Rasheed, R.K.; Tambyrajah, V. Novel solvent properties of choline chloride/urea mixtures Chem. Commun. 2003, 1, 70-71. [CrossRef]

19. Chen, B. Modeling for Solvent Extraction of Copper Based on Kernel Partial Least Squares Method. Shifayejin 2021, 40, 260-266.

20. Cao, X.; Xu, L.; Shi, Y. Electrochemical behavior and electrodeposition of cobalt from choline chloride-urea deep eutectic solvent. Electrochim. Acta 2019, 295, 550-557. [CrossRef]

21. Abbott, A.P.; Harris, R.C.; Ryder, K.S. Application of hole theory to define ionic liquids by their transport properties. J. Phys. Chem. B 2007, 111, 4910-4913. [CrossRef]

22. Hua, Y. Introduction to Kinetics of Processing Metallurgy; Metallurgical Industry Press: Beijing, China, 2004; pp. 192-193. (In Chinese)

23. Wang, L.; Gao, H.; Song, S. Experimental and kinetic study of zinc leaching from metallurgical slag by 5-sulfosalicylic acid. Physicochem. Probl. Miner. Process. 2021, 57, 8-20. [CrossRef]

24. Nie, W.; Wen, S.; Feng, Q.; Liu, D.; Zhou, Y. Mechanism and kinetics study of sulfuric acid leaching of titanium from titaniumbearing electric furnace slag. Mater. Res. Technol. 2020, 9, 1750-1758. [CrossRef] 